\title{
Chemical Lecture Demonstrations: An Opportunity for Engagement through Collections, Instruction, and Reference
}

\author{
David E. Hubbard \\ Science \& Engineering Librarian and Associate Professor \\ Texas A\&M University Libraries \\ College Station, TX 77843
}

\begin{abstract}
Chemical lecture demonstrations have been used as a pedagogical tool since at least the founding of chemistry as a discipline in the $1600 \mathrm{~s}$. This paper describes how science librarians can engage chemistry faculty and students through chemical lecture demonstrations. This paper describes chemical lecture demonstrations - including history and efficacy - and discusses how science librarians can engage chemistry faculty and students through collections, instruction, and reference in support of this pedagogy. In addition to outlining a research guide and lesson plan for chemical lecture demonstrations, this paper identifies chemical lecture demonstration monographs found in WorldCat ${ }^{\circledR}$ and analyzes the holdings of those monographs within the thirtysix-member Greater Western Library Alliance (GWLA) consortium.
\end{abstract}

\section{Introduction}

Chemical lecture demonstrations, which are lively displays of chemical principles to an audience of students or the general public, are an important pedagogical tool used to educate and engage. Monographs have been one of the major means to educate others on how to conduct these demonstrations. The purpose of this bibliographical investigation is to identify and examine chemical lecture demonstration monograph holdings within the thirty-six-member Greater Western Library Alliance (GWLA) consortium (Greater Western Library Alliance n.d.), and to describe local support for chemical lecture demonstrations through collections, instruction, and reference. The paper first describes and reviews the history of the chemical lecture demonstration, followed by a discussion of its use and efficacy. The paper concludes with identification and analysis of chemical lecture demonstration monograph holdings. 
This is an Accepted Manuscript of an article published by Taylor \& Francis Group in Science \& Technology Libraries on 11/21/2017, available online: https://www.tandfonline.com/doi/abs/10.1080/0194262X.2017.1389667

\section{Chemical lecture demonstration}

One of the more succinct definitions of the chemical lecture demonstration is simply "...an illustration of a point in a lecture or lesson by means of something other than conventional visual-aid apparatus" (Taylor 1988: 59). A more student-centered view is that it 'help[s] to focus students' attention on chemical behavior and chemical properties, and to increase students' knowledge and awareness of chemistry..." (Shakhashiri 1983: xviii). In this paper, chemical lecture demonstrations refer to both those conducted during a credit-bearing chemistry class and those open to the public as one-time events. The former is used primarily to illustrate a principle or theory during a standard lecture, whereas the latter is used to increase the public's understanding and interest in chemistry, especially for those in K-12. There are some differences between those two audiences and venues, but there are more similarities than differences.

\section{History of the chemical lecture demonstration}

The chemical lecture demonstration has been used as a pedagogical tool since chemistry was introduced into university curricula in the 1600s and continues to be used today (Jensen 1991; Kauffman 1996; Shakhashiri 2011). The origins of the chemical lecture demonstration emerged from lecture demonstrations conducted in Renaissance medical schools where the first university chemistry courses were taught (Jensen 1991), though the lecture demonstration itself could be traced back further (Kauffman 1996). The Golden Age of chemistry lecture demonstrations were the 1800s. The Royal Institution of Great Britain, an independent charitable organization, was founded in 1799 with a mission of developing scientific programs to educate and engage the public. Humphrey Davy was appointed assistant lecturer and director of the chemical laboratory. He became known as an excellent lecturer and his lecture demonstrations were well received. Demonstrating current scientific developments was 
This is an Accepted Manuscript of an article published by Taylor \& Francis Group in Science \& Technology Libraries on 11/21/2017, available online: https://www.tandfonline.com/doi/abs/10.1080/0194262X.2017.1389667

part of the appeal, but so were the theatrics. Davy later hired Michael Faraday. Faraday became director of the chemical laboratory in 1825 and started the Christmas Lecture series the following year. This public lecture was intended for a juvenile audience and continues to this day (Kauffman 1996; Royal Institution 2014; Toftlund 1988).

From the 1600 s throughout most of the 1800 s, lecture demonstrations were an integral part of the university chemistry curriculum (Jensen 1991). In the early 1800s, chemistry teaching laboratories emerged in Europe and there was a pedagogical shift to the applied. The establishment of the "first" chemistry teaching laboratory by Justus von Liebig at the University of Giessen in 1820s changed how chemistry was taught. Liebig's model provided the practical training needed for the flourishing industries of the Industrial Revolution. Chemistry teaching laboratories were slowly adopted in the U.S. during the 1800s, but accelerated in the late 1800s. By the end of the 1800s, chemistry teaching laboratories were a common feature within U.S. universities (Lewenstein 1989). Illustration of principles once addressed by lecture demonstrations, where moved to the teaching laboratory to some extent.

Despite evolving pedagogy, use of the chemical lecture demonstrations continued into the $20^{\text {th }}$ and $21^{\text {st }}$ centuries. One of the key figures involved in developing, expanding, and promoting their use in the early 20th century was Hubert Alyea at Princeton University (Kauffman 1996). He developed an approach to conducting demonstrations using an overhead projector or inclined plane called the Tested Overhead Projection Series (or TOPS), which allowed an instructor to project small benchtop experiments onto a large screen (Alyea 1955; Shakhashiri 1997). Another important figure who advanced the chemical lecture demonstration was Gilbert Haight at the University of Illinois. He has not received the acknowledgement deserved since he did not publish much on the topic; however, Haight was a pioneer in using television and multimedia for teaching chemistry that included videotaped lecture demonstrations (Student Life and Cultural Archival Program 2002). The current reigning champion of chemical demonstrations is Bassam Shakhashiri at the University of Wisconsin (Kauffman 1996). His five- 
This is an Accepted Manuscript of an article published by Taylor \& Francis Group in Science \& Technology Libraries on 11/21/2017, available online: https://www.tandfonline.com/doi/abs/10.1080/0194262X.2017.1389667

volume set titled Chemical Demonstrations: A Handbook for Teachers of Chemistry (Shakhashiri 1983, $1985,1989,1992,2011)$ is considered to be the bible for chemical demonstrations. There are too many other individuals, past and present, to name all who have contributed to the development of this pedagogy.

Based on the regular inclusion in the Journal of Chemical Education and presentations focusing on lecture demonstrations at the Biennial Conference on Chemical Education, lecture demonstrations are clearly still used in chemical education. Unfortunately, there are no recent multi-institution studies of pedagogical methods employed by university teaching faculty to quantify or substantiate the use of chemical lecture demonstrations further. There is, however, evidence that $58 \%$ of secondary school chemistry teachers regularly use chemical lecture demonstrations (Price and Brooks 2012). This statistic has implications for universities involved in teacher education. In addition to the classroom, many universities also host public chemistry demonstrations for K-12 STEM outreach. These public outreach efforts are often one-time events during National Chemistry Week, though it may also be part of an ongoing outreach program. These public chemistry demonstrations are conducted by chemistry faculty or by American Chemical Society student chapters under the auspices of the chemistry department or faculty advisor.

\section{Efficacy of chemical lecture demonstrations}

There is general consensus that chemical lecture demonstrations are beneficial and can contribute to student learning and increase interest in chemistry, though the efficacy of lecture demonstrations depends on appropriateness of the demonstration and level of engagement (Beall 1991; Shakhashiri 1992; Trna and Trnova 2015). A demonstration by itself may be insufficient; it needs an interactive component to engage students, and should employ a constructivist approach that facilitates active 
This is an Accepted Manuscript of an article published by Taylor \& Francis Group in Science \& Technology Libraries on 11/21/2017, available online: https://www.tandfonline.com/doi/abs/10.1080/0194262X.2017.1389667

inquiry versus passive observation. One such interactive approach is Predict-Observe-Explain (POE), which prompts students to predict what will occur prior to the demonstration, observe, and then explain what occurred (Badiola et al. 2013; Treagust 2007). The responses can be collected through a variety of means including discussion, worksheets, personal response systems (i.e., clickers), etc. The use and assessment of interactive lecture demonstrations are newer developments in the evolution of the chemical lecture demonstration.

The use of video demonstrations, instead of live demonstrations, is also a newer development in this 400-year old pedagogical practice. These videos, especially of public demonstrations, can assist those interested in learning something about the "theatrics" that is often associated with demonstrations. Chemical demonstration videos can be found freely available online from both reputable [e.g., Dr. Peter Wothers Open Lectures (University of Cambridge 2011)] and less than reliable sources. In many cases, these freely available video demonstrations lack the details needed to actually conduct the demonstrations, including safety precautions, that monographs and journal articles often contain. In addition to freely available online videos, there are videos available by subscriptions and purchase. A reputable example of the former is the Chem Ed Xchange from the American Chemical Society's Division of Chemical Education that offers 280 video demonstrations (ACS Division of Chemical Education 2017). In terms of purchasing video chemical demonstrations, Flinn Scientific is one of the larger producers of DVDs and offers a number of their videos online for free (Flinn Scientific 2017).

\section{Background - Texas A\&M University and chemical lecture demonstrations}

As mentioned in the Introduction, chemical lecture demonstrations are performed both during creditbearing chemistry classes and one-time educational events. The use of the chemical lecture demonstration at Texas A\&M University (TAMU) in the classroom is not known, but anecdotal evidence 
This is an Accepted Manuscript of an article published by Taylor \& Francis Group in Science \& Technology Libraries on 11/21/2017, available online: https://www.tandfonline.com/doi/abs/10.1080/0194262X.2017.1389667

indicates that it is periodically used in some lower-level, large undergraduate lectures. The public chemical lecture demonstrations are much easier to quantify. TAMU started the Chemistry Road Show, a traveling educational public outreach program, in 1985 (TAMU College of Science 2008). In 2014, there were eighty-three shows reaching more than 22,000 people throughout the state (Hutchins 2015). The Chemistry Road Show demonstrations are coordinated and conducted by a TAMU faculty member and assisted by undergraduate volunteers. The University Libraries has supported the Chemistry Road Show through collections, instruction, and reference. Monographs describing lecture demonstrations, including chemical lecture demonstrations, have been actively sought and acquired. Instructional sessions were provided to the Chemistry Road Show students and related one-credit chemistry service learning courses. Students in the latter volunteer for the Chemistry Road Show and developed their own demonstration. An outline of the lesson plan used for the fifty-minute instructional session is shown in Appendix A. A research guide (LibGuide) was also created to support the course and serve as reference tool that provides links to monographs, video demonstrations, education databases, and search strategies to locate articles on chemical demonstrations (Hubbard 2017). There are few follow-up reference consultations after the instruction sessions, but the research guide supports reference consultations when working with students. There is also interest from community users (e.g., home schoolers), in-person and email, and the research guide is often the starting point for those reference consultations and questions.

\section{Purpose and questions}

To further support chemical lecture demonstrations at TAMU, a collection development project was initiated to address the following questions: (1) What chemical lecture demonstration monographs 
This is an Accepted Manuscript of an article published by Taylor \& Francis Group in Science \& Technology Libraries on 11/21/2017, available online: https://www.tandfonline.com/doi/abs/10.1080/0194262X.2017.1389667

exist, and (2) What chemical lecture demonstration monographs do the TAMU Libraries and other Greater Western Library Alliance (GWLA) member libraries own.

The interest and rationale in the second question are manifold. First, using a peer group - like the GWLA consortium - allows for comparison of relative collection strengths (i.e., benchmarking). Using a peer group in this manner also allows one to gain insights from the collective wisdom of the group in that it represents monographs the peer group needed or deemed potentially useful, as well as those that they did not. In general, the thirty-six-member consortium represents a sampling of mainly academic research libraries; more than half of the GWLA members are also Association of Research Libraries' members. Another rationale is that GWLA offers its member libraries a service called BorrowltNow that allows patrons (or their libraries) to place expedited interlibrary loan requests with longer loan periods within the GWLA consortium. Should TAMU Libraries not own a particular book, it would be useful to know if another GWLA library owns it. If so, a copy could be easily borrowed from another consortial member. If not, a copy could be purchased by TAMU Libraries. The purchase not only serves local needs, but the larger GWLA consortium through BorrowltNow and could be viewed as informal consortial collection development.

There are a few approaches one could use to answer these research questions. Chemical lecture demonstration monographs could be identified using bibliographies, such as Katz $(1991,2005)$ and Kauffman (1996), that include lecture demonstration monographs and other resources. Another approach is to search OCLC's WorldCat ${ }^{\circledR}$ using call numbers or Library of Congress Subject Headings (LCSH). With respect to LCSH, chemical lecture demonstration monographs are typically assigned "Chemistry - Experiments." This LCSH includes both laboratory experiments and demonstrations, which is problematic since there are many more materials on laboratory experiments compared to demonstrations. Based on chemical lecture demonstration monographs listed in the three bibliographies mentioned above and personal experience of the author, most are classified under 
This is an Accepted Manuscript of an article published by Taylor \& Francis Group in Science \& Technology Libraries on 11/21/2017, available online: https://www.tandfonline.com/doi/abs/10.1080/0194262X.2017.1389667

Library of Congress Classification (LCC) QD43. While QD43 also yields both laboratory experiments and demonstrations, it is more focused on demonstrations compared to LCSH "Chemistry - Experiments." Regardless of approach - bibliographies, LCSH, or LCC - WorldCat ${ }^{\circledR}$ can be used to identify monographs available and holdings at other libraries.

\section{Methods}

Chemical lecture demonstration monographs were identified by searching QD43 in WorldCat ${ }^{\circledast}$ using the Expert Search mode, then limiting the format to "Books" and the language to "English." A decision was made to focus on monographs held by twenty-five or more libraries since those under that value were mainly variant records of those held by twenty-five or more libraries or self-published works. The WorldCat ${ }^{\circledR}$ records were exported to EndNote and then deduplicated. Since QD43 also includes both laboratory manuals and monographs, each title was examined to ensure it mainly contained demonstrations versus laboratory experiments. Each of the chemical lecture demonstration monographs identified was then looked up in WorldCat $^{\circledR}$ and the holdings of those titles were determined for the 36 GWLA libraries. In cases of multiple editions, any edition or imprint was deemed acceptable to be counted as owned by a GWLA library. Local library catalogs were consulted for multiple-volume sets to check holdings of individual volumes. With the exception of TAMU Libraries, holdings for the GWLA libraries were coded (e.g., GWLA1, GWLA2, etc.) to maintain anonymity of the GWLA members. In addition to holdings, chemical lecture demonstration monographs by publication year was also determined. It is important to note that using WorldCat $^{\circledR}$ and reporting results as described requires permission from OCLC, which was obtained for this investigation (Personal Communication, B.A. Crocco, 2016). There are limitations to this approach and those will be addressed later in the Discussion. 
This is an Accepted Manuscript of an article published by Taylor \& Francis Group in Science \& Technology Libraries on 11/21/2017, available online: https://www.tandfonline.com/doi/abs/10.1080/0194262X.2017.1389667

\section{Results}

The search of WorldCat ${ }^{\circledR}$ identified 101 titles meeting the initial criteria (i.e., QD43, English language, Books format, and owned by 25 or more libraries). After examining the 101 titles, only twenty-two titles were determined to mainly focus on chemical lecture demonstrations. The holdings of each of the GWLA libraries are summarized in Figure 1 and complete citations are given in Appendix B. Only the most recent edition or most widely held imprint is listed in Appendix B. None of the thirty-six GWLA libraries own all twenty-two titles. Collectively, GWLA libraries own twenty-one of twenty-two titles. The holdings for individual libraries range between one (GWLA36) and fourteen (GWLA1) with a mean and median of seven titles. TAMU Libraries owns twelve of twenty-two titles. Shakhashiri $(1983,1985,1989$, 1992, 2011) and Summerlin and Ealy $(1985,1988)$, the two most widely held by far, were comprised of five and two volumes, respectively. While Shakhashiri $(1983,1985,1989,1992,2011)$ was the most widely held, only eight of the thirty-three GWLA libraries that hold Shakhashiri have all five volumes. Similarly, only twenty-two of the thirty-two GWLA libraries holding Summerlin and Ealy $(1985,1988)$ owned both volumes of the two-volume set. Figure 2 shows the twenty-two titles by publication year (decade) based on latest edition. The twenty-two titles were published between 1892 and 2011 with the 1990s being the most prolific period. Since each volume of Bilash, Gross, and Koob $(1995,1998)$ and Shakhashiri $(1983,1985,1989,1992,2011)$, were published separately in different years, each volume is counted separately in Figure 2 for the decade published. 


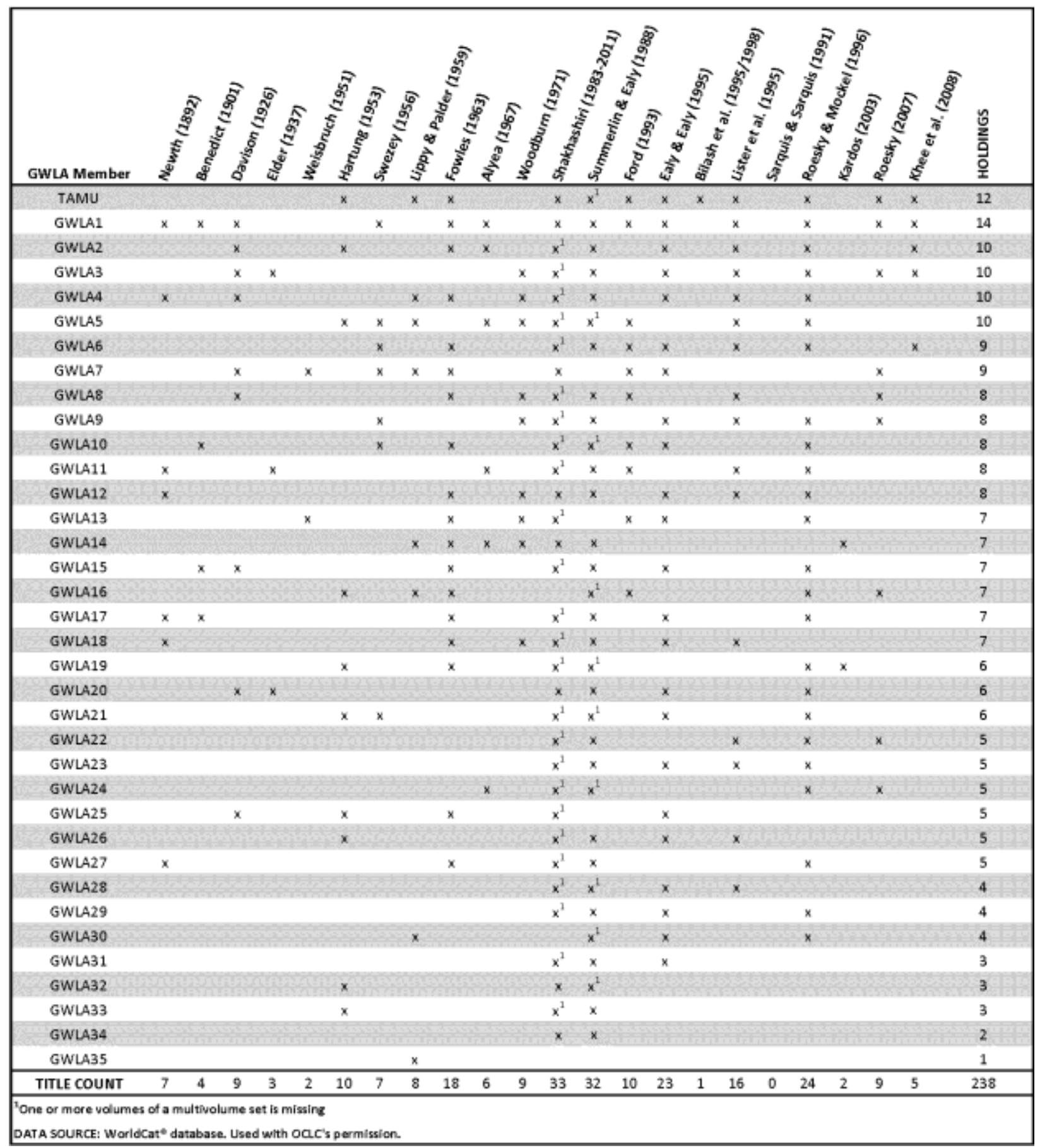

Figure 1. GWLA holdings of chemical lecture demonstration monographs. 


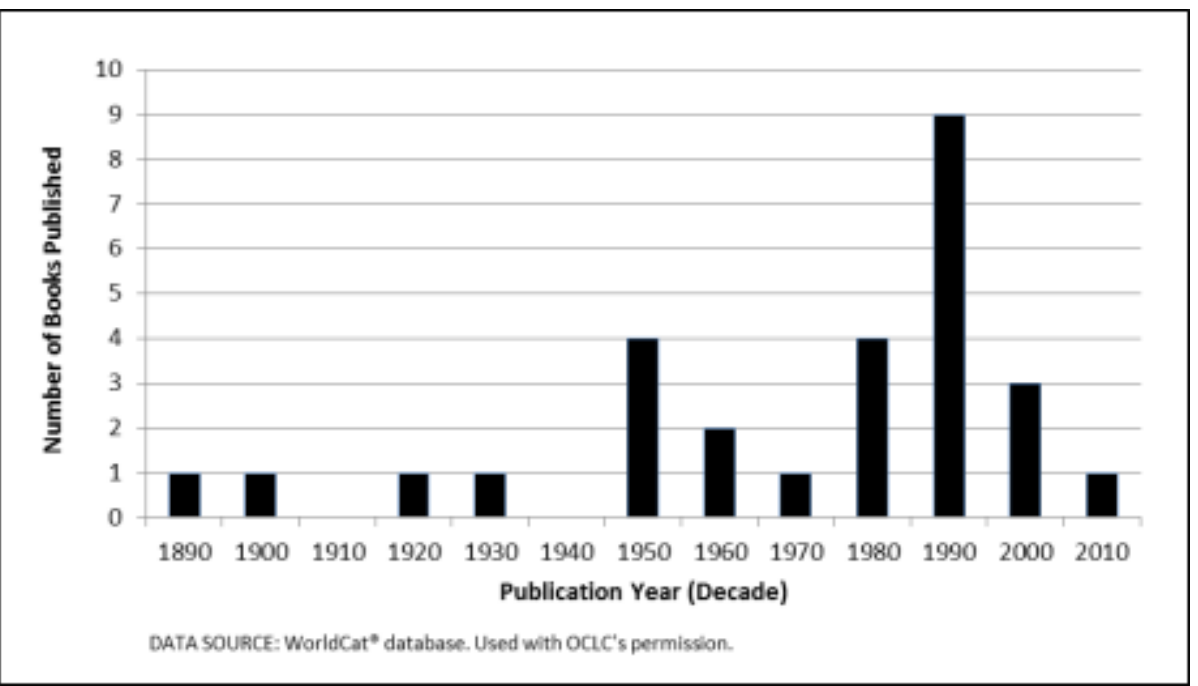

Figure 2. Chemical lecture demonstration monographs by decade.

\section{Discussion}

The search for LCC QD43 in WorldCat ${ }^{\circledR}$ was effective at identifying a number of chemical lecture demonstration monographs. Its effectiveness is evidenced by the fact that the approach identified many listed in Katz $(1991,2005)$ and Kauffman (1996), as well as several monographs that were not listed. Many of the latter were published since those bibliographies were published. These bibliographies included a few notable print monographs that were not included in the search of QD43. Those omissions were A Course of Six Lectures on the Chemical History of a Candle (Faraday 1861), Lecture Demonstrations in General Chemistry (Arthur 1939), Tested Demonstrations in Chemistry (Alyea and Dutton 1965), Demonstrating Chemistry (Humphreys 1983), and Tested Demonstrations in Chemistry (Gilbert 1994). Those five monographs were classed into other LCCs: Faraday (QD38), Arthur (QD42) Alyea and Dutton (QD45), Humphreys (QD45), and Gilbert (QD45). While a few notable omissions were located in QD45, that LCC primarily focuses on "laboratory manuals" and would yield few other chemical lecture demonstration monographs.

The oldest book identified using this study's approach is Chemical Lecture Experiments (Newth 1892); however, this is more recent than Faraday's A Course of Six Lectures on the Chemical History of a Candle 
This is an Accepted Manuscript of an article published by Taylor \& Francis Group in Science \& Technology Libraries on 11/21/2017, available online: https://www.tandfonline.com/doi/abs/10.1080/0194262X.2017.1389667

(1861) and several older known texts listed in the three aforementioned bibliographies. For example, the study's approach missed what William B. Jensen (1991) referred to as the first American chemical demonstration book, Sadtler's Chemical Experimentation: Being a Hand-Book of Lecture Experiments in Inorganic Chemistry (1877), since it is held by fewer than tweny-five libraries. The most recent book identified is Chemical Demonstrations: A Handbook for Teachers of Chemistry Volume 5 (Shakhashiri, 2011). The 1990s were the most prolific period for publication of monographs on chemical lecture demonstrations and correspond with renewed interest in creating more interactive, engaging lectures, as well as increased outreach efforts to attract K-12 students into STEM.

\section{Collection development considerations}

The 36 GWLA libraries own twenty-one of twenty-two titles, though it is important to note that it does not include every edition or imprint; any edition or imprint was deemed acceptable. There were also two multivolume sets that were often incomplete. Considering that Shakhashiri's five-volume set is often referred to as the bible when it comes to chemical lecture demonstrations and its modest cost, librarians might check their collections and consider completing the set. Science librarians might also consider some of the recent monographs listed in Appendix B for their collections. It should be noted that despite the age of some of the monographs listed in Appendix B, lecture demonstrations discussed in those older texts are still conducted, maybe in an updated or modified version, today. Modifying an older classic chemical demonstration - making it safer or more appropriate to today's audiences - is something you see in in the chemical educational literature. One other consideration is that some of these titles are not widely held, so libraries and consortial members should be cautious during QD deselection projects if these materials are to be accessible in the future. 
This is an Accepted Manuscript of an article published by Taylor \& Francis Group in Science \& Technology Libraries on 11/21/2017, available online: https://www.tandfonline.com/doi/abs/10.1080/0194262X.2017.1389667

\section{Limitations}

There are some limitations to this approach. As indicated above, not all chemical lecture demonstrations are classed in QD43. Some of the search limits used may have excluded "rarer" chemical lecture demonstration monographs held by fewer than twenty-five libraries or in languages other than English. The monographs identified in this investigation were specifically for demonstrations, which was either explicitly stated purpose in the text of the book or evident by its content. Monographs that focused on laboratory experiments with a few demonstrations were excluded. As Alyea's TOPS: Tested Overhead Projection Series (1967) demonstrates, even small benchtop "laboratory experiments" can be projected and used for demonstrations, though this investigation sought to identify monographs where demonstrations were the focus versus laboratory experiments. As noted in the Results, not all editions and imprints of the twenty-two chemical lecture demonstration monographs identified are listed in Appendix B. Occasionally there are slight variations in the citation from one edition or imprint to another, namely the title, so librarians searching local catalogs to check their holdings using Appendix B need to keep that in mind. While this approach was deemed effective at locating chemical lecture demonstration monographs, some of the older bibliographies should also be consulted to supplement this more formal approach. Lastly, it should be noted that there are also lecture demonstration monographs in general science (Q) and physics (QC) that could be used in a chemical lecture demonstration; however, those are beyond the scope of this investigation.

\section{Conclusion}

In addition to using chemical lecture demonstrations in chemistry classrooms, many universities host public chemistry demonstrations as outreach to $\mathrm{K}-12$ and the larger community. Chemical lecture demonstrations, especially public events, create a unique opportunity for science librarians to 
This is an Accepted Manuscript of an article published by Taylor \& Francis Group in Science \& Technology Libraries on 11/21/2017, available online: https://www.tandfonline.com/doi/abs/10.1080/0194262X.2017.1389667

collaborate with faculty and students in support of these educational and outreach initiatives. This can be accomplished through collections, instruction, and reference. This paper outlined a lesson plan for instruction and identified the most widely held chemical lecture demonstration monographs. A fairly strong monograph collection in this area can be acquired for a nominal cost and provide an opportunity for greater engagement with faculty, ACS student chapters, and even the local community.

\section{Acknowledgements}

I would like to thank the reviewers for their feedback and helpful comments. It certainly improved the quality of the manuscript and I'm greatly appreciative of their efforts. I'm also indebted to the TAMU Department of Chemistry for the opportunity and their insights.

\section{References}

ACS Division of Chemical Education. Chem Ed Xchange -Videos. 2017. Washington, DC: American Chemcial Society. Accessed May 12, 2017. https://www.chemedx.org/page/video

Alyea, H. N. 1955. Tested demonstrations in general chemistry. Journal of Chemical Education. 32 (1): 28-29. doi: 10.1021/ed032p28

Alyea, H. N. 1967. TOPS: Tested overhead projection series. Easton, PA: Division of Chemical Education of the American Chemical Society.

Alyea, H. N., and F. B. Dutton. 1965. Tested demonstrations in chemistry. 6th ed. Easton, PA: Division of Chemical Education of the American Chemical Society.

Arthur, P. 1939. Lecture Demonstrations in General Chemistry. New York: McGraw-Hill.

Badiola, K. A., K. Bartimote-Aufflick, A. J. Bridgeman, A. V. George, S. T. Hudson, C. Neto and S. A. Schmid. 2013. Using interactive lecture demonstrations to invigorate chemistry lectures.. In Proceedings of The Australian Conference on Science and Mathematics Education, edited by M. Sharma and A. Yeung. https://openjournals.library.sydney.edu.au/index.php/IISME/article/view/7072/7583 (accessed May $5,2017)$

Bilash, B., G. R. Gross, and J. K. Koob. 1995. A Demo a Day: A Year of Chemical Demonstrations. Batavia, IL: Flinn Scientific.

Bilash, B., G. R. Gross, and J. K. Koob. 1998. A Demo a Day: A Year of Chemical Demonstrations. Vol. 2. Batavia, IL: Flinn Scientific.

Beall, H. 1991. Report on the WPI Conference: New practical examples for general chemistry. Journal of Chemical Education. 68 (5): 381-382. doi:10.1021/ed068p381 
This is an Accepted Manuscript of an article published by Taylor \& Francis Group in Science \& Technology Libraries on 11/21/2017, available online: https://www.tandfonline.com/doi/abs/10.1080/0194262X.2017.1389667

Faraday, M., and W. Crookes. 1861. A Course of Six Lectures on the Chemical History of a Candle. New York: Harper \& Brothers.

Flinn Scientific. 2017. Chemistry Video Topics. Batavia, IL: Flinn Scientific. https://elearning.flinnsci.com/Topics.aspx (accessed May 12, 2017)

Gilbert, G. L., ed. 1994. Tested Demonstrations in Chemistry. Easton, PA: Division of Chemical Education of the American Chemical Society.

Greater Western Library Alliance. n.d. About GWLA. Prairie Village, KS: Greater Western Library Alliance. http://www.gwla.org/ (accessed May 5, 2016)

Hubbard, D. E. 2017. Chemical Demonstrations. College Station, TX: Texas A\&M University Libraries. Accessed May 12, 2017. http://tamu.libguides.com/c.php?g=609481\&p=4263399

Humphreys, D. A. 1983. Demonstrating chemistry: 160 experiments to show your students. Hamilton, Ontario: printed by the author.

Hutchins, S. 2015. Science in motion. Spirit Magazine. College Station, TX: Texas A\&M University. Accessed March 14, 2016. http://spiritarchive.txamfoundation.com/2015Summer/ html5/ index.html?page $=30$

Jensen, W. B. 1991. To demonstrate the truths of "chymistry." Bulletin of the History of Chemistry. 10: 315.

Katz, D. A. 1991. Science demonstrations, experiments, and resources: A reference list for elementary through college teachers emphasizing chemistry with some physics and life science. Journal of Chemical Education. 68 (3): 235-244. doi:10.1021/ed068p235

Katz, D. A. 2005. Science demonstrations, experiments, and resources: A reference list for elementary through college teachers emphasizing chemistry with some physics and life science. Accessed June 24, 2016. http://www.chymist.com/Booklist.pdf

Kauffman, G. B. 1996. Lecture demonstrations, past and present. The Chemical Educator. 1 (5): 1-33. doi:0.1007/s00897960057a

Lewenstein, B. V. 1989. "To Improve our knowledge in nature and arts": A history of chemical education in the United States. Journal of Chemical Education. 66 (1): 37-44. doi: 10.1021/ed066p37

Newth, G. S. 1892. Chemical lecture experiments: Non-metallic elements. London: Longmans, Green \& Co.

Price, D. S., and D. W. Brooks. 2012. Extensiveness and perceptions of lecture demonstrations in the high school chemistry classroom. Chemistry Education Research and Practice. 13 (4): 420-427. doi: 10.1039/C2RP20014G

Royal Institution. 2014. About the Christmas Lectures. London: Royal Institution. Accessed March 14, 2016. http://www.rigb.org/christmas-lectures/about

Sadtler, S. P. 1877. Chemical experimentation: Being a hand-book of lecture experiments in inorganic chemistry. Louisville, KY: J. P. Morton.

Shakhashiri, B. Z. 1983. Chemical demonstrations: A handbook for teachers of chemistry. Vol. 1. Madison: University of Wisconsin Press. 
This is an Accepted Manuscript of an article published by Taylor \& Francis Group in Science \& Technology Libraries on 11/21/2017, available online: https://www.tandfonline.com/doi/abs/10.1080/0194262X.2017.1389667

Shakhashiri B. Z. 1985. Chemical demonstrations: A handbook for teachers of chemistry. Vol. 2. Madison: University of Wisconsin Press.

Shakhashiri B. Z. 1989. Chemical demonstrations: A handbook for teachers of chemistry. Vol. 3. Madison: University of Wisconsin Press.

Shakhashiri B. Z. 1992. Chemical demonstrations: A handbook for teachers of chemistry. Vol. 4. Madison: University of Wisconsin Press.

Shakhashiri, B.Z. 1997. Hubert N. Alyea, 1903-1996. Journal of Chemical Education. 74(1):20-21.

Shakhashiri, B. Z. 2011. Chemical demonstrations: A handbook for teachers of chemistry. Vol. 5. Madison: University of Wisconsin Press.

Student Life and Cultural Archival Program. 2002. Oral History Project - Gilbert Pierce Haight. Urbana, IL: University of Illinois. Accessed May 5, 2017. https://archives.library.illinois.edu/slcold/ researchguides/oralhistory/record_series/

Summerlin, L. R., and J.L. Ealy. 1985. Chemical demonstrations: A sourcebook for teachers. Washington, DC: American Chemical Society.

Summerlin, L. R., and J. L. Ealy. 1988. Chemical demonstrations: A sourcebook for teachers. 2nd ed. Washington, DC: American Chemical Society.

Taylor, C. 1988. The art and science of lecture demonstration. Bristol, England: Adam Hilger.

TAMU College of Science. 2008. Texas A\&M mourns loss of beloved chemist and teacher. College Station, TX: Texas A\&M University. Accessed March 14, 2016 http://www.science.tamu.edu/news/story.php?story_ID=581\#.Wbhpwk0Uqcw

Toftlund, H. 1988. History of the lecture demonstration. Education in Chemistry. 25: 109-111.

Treagust, D. 2007. General instructional methods and strategies. In Handbook of research on science education, edited by S. K. Abell and N. G. Lederman. 373-392. New York: Routledge.

Trna, J., and E. Trnova. 2015. Revival of demonstration experiments in science education. In Proceedings of the International Conference of Education in Mathematics, Science \& Technology, edited by I. Sahin, S. A., Kiray, S. Alan. Accessed May 14, 2014. http://2015.icemst.com/ICEMST2015_Proceeding_Book.pdf?rnd=405974931

University of Cambridge. 2011. Dr. Peter Wothers Open Lectures. Cambridge: University of Cambridge. Accessed May 12, 2017. https://sms.cam.ac.uk/collection/1182855 


\section{Appendix A: Outline of Chemical Demonstration Lesson Plan}

Learning Objectives

- Students will be able to locate books and articles on chemical demonstrations

- Students will be able to describe the advantages/disadvantages of using subject headings

- Students will be able to describe the value and limitations of chemical demonstration videos

Overview of Chemical Demonstration LibGuide

Books

- Discuss Shakhashiri's books and other selected books listed on the LibGuide

- Demonstrate library catalog keyword and LCSH searches

o LCSH: "Chemistry - Experiments."

- ACTIVTY: Students search for books in the catalog and report out

- Highlight LC areas with chemistry demonstrations:

o QD43 (main), Q164, QD38, QD45.

Journal Articles

- Discuss journals with science demonstrations and circulate

- Demonstrate searches in ERIC and Education Full-

Text Keywords: Boyle's Law, Thermodynamics, etc.

- ERIC Descriptors: Demonstrations (Educational)

- Combine Descriptor and Keywords

- DE "Demonstrations (Educational)" and thermodynamics

- ACTIVTY: Assign a chemical principle to be illustrated for each student (e.g., Boyle's Law) and have them search ERIC or Education Full-Text to locate journal articles for a demonstration.

Videos

- Discuss value and limitations of chemical demonstration videos

- Show a few video clips of selected online videos listed on LibGuide

Free Time to Search as Time Permits 
This is an Accepted Manuscript of an article published by Taylor \& Francis Group in Science \& Technology Libraries on 11/21/2017, available online: https://www.tandfonline.com/doi/abs/10.1080/0194262X.2017.1389667

\section{Appendix B: Chemical Lecture Demonstration Monographs}

Alyea, H. N. 1967. TOPS: Tested overhead projection series. Easton, PA: Division of Chemical Education of the American Chemical Society.

Benedict, F. G. 1901. Chemical lecture experiments. New York: Macmillan.

Bilash, B., G. R. Gross, and J. K. Koob. 1995/1998. A demo a day: A year of chemical demonstrations. Vol. 1-2. Batavia, IL: Flinn Scientific.

Davison, H. F. 1926. A collection of chemical lecture experiments. New York: Chemical Catalog Co.

Ealy, J.B., and J. L. Ealy. 1995. Visualizing Chemistry: Investigations for Teachers. Washington, DC: American Chemical Society.

Elder, A. L. 1937. Demonstrations and experiments in general chemistry. New York: Harper \& Brothers.

Ford L. A., and G. E. Winston. 1993. Chemical magic. 2nd ed. New York: Dover.

Fowles, G. 1963. Lecture experiments in chemistry. London: George Bell.

Hartung, E. J. 1953. The screen projection of chemical experiments. Melbourne: University Press.

Kardos, T. 2003. Chemistry. Portland, ME: J. W. Walch.

Khee S. W. 2008. CheMagic: 50 chemistry classics and magical tricks. Hackensack, NJ: World Scientific.

Lippy J. D., and E. L. Palder. 1959. Modern chemical magic. Harrisburg, PA: Stackpole Co.

Lister, T., C. O'Driscoll, and N. Reed. 1995. Classic chemistry demonstrations. London: Royal Society of Chemistry.

Newth, G. S. 1892. Chemical lecture experiments: Non-metallic elements. London: Longmans, Green \& Co.

Roesky, H. W. 2007. Spectacular chemical experiments. Weinheim: Wiley-VCH.

Roesky, H.W., and M. K Möckel. 1996. Chemical curiosities: Spectacular experiments and inspired Quotes. New York: VCH.

Sarquis, M., and J. Sarquis. 1991. Fun with chemistry: A guidebook of $K-12$ activities from the Institute for Chemical Education. Madison: University of Wisconsin.

Shakhashiri, B. Z. 1983-2011. Chemical Demonstrations: A Handbook for Teachers of Chemistry. Madison: University of Wisconsin Press.

Summerlin, L. R., and J. L. Ealy. 1988. Chemical demonstrations: A sourcebook for teachers. 2 nd ed. Washington, DC: American Chemical Society.

Swezey, K. M. 1956. Chemistry magic. New York: McGraw-Hill.

Weisbruch, F. T. 1951. Lecture demonstration experiments for high school chemistry. St. Louis: Educational Publishers.

Woodburn, J. H., L. R. Sanford, and W. J. Brawley. 1971. Demonstrations and activities for high school chemistry. West Nyack, NY: Parker Pub Co. 